\title{
An uncommon case of scrotal calcinosis
}

Zaahil Ahamed $^{1}$, Nilesh Nettipola $^{1}$, Asha Dissanayaka $^{1}$, Shirani Samarathunga $^{1}$, Bingumal Jayasundara $^{1}$

(Index words: calcinosis cutis, idiopathic calcification, scrotum)

\section{Case presentation}

A 29-year-old Sri Lankan male was reviewed at the surgical clinic as he developed multiple, painless scrotal lumps over two and a half years. Patient could not recall precipitating incidents like infection or trauma initiating these lesions. First, he noted a couple of soft lumps which gradually grew in number and progressively became hard. There was no pain or discharge from these lumps. On examination, the patient had multiple hard, non-tender, immobile lumps in scrotal skin beside median raphe (Figure 1A). Clinically, both testes were normal and patient did not have similar lumps anywhere else in the body with an unremarkable systemic examination. His inflammatory markers, Parathyroid hormonal assay, serum calcium and phosphate levels were normal. Plain radiography showed numerous nodular opacifications in the scrotum compatible with palpable lesions (Figure 1B). A clinical diagnosis of Scrotal Calcinosis (SC) was made. The patient underwent surgical excision of affected scrotal skin and primary closure. Histology showed granules and globules of basophilic calcification limited to scrotal dermis, preserving segments of Dartos muscle examined. Foreign body giant cell reaction was evident around calcific globules that lacked an epithelial lining, confirming the diagnosis of Idiopathic SC (Figure 1C). The patient had excellent cosmetic outcome with no recurrence at six months.

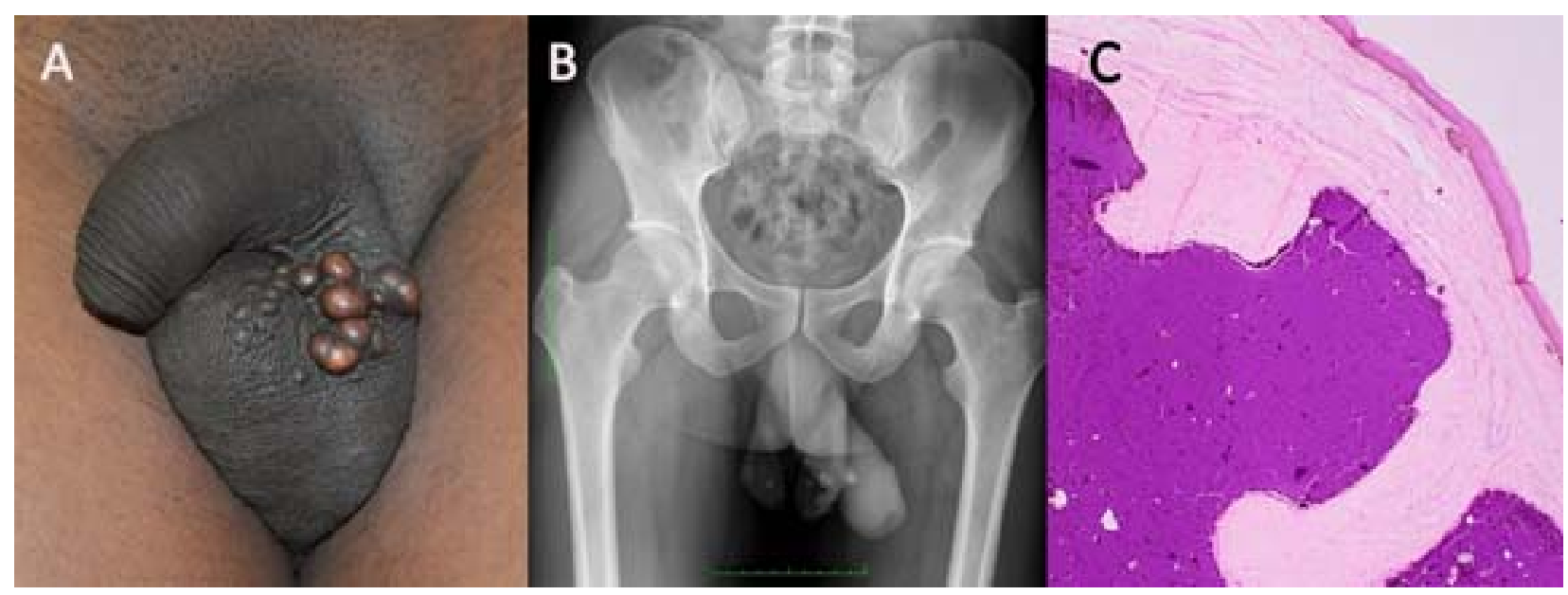

Figure 1. A-Multiple nodules seen in the scrotal skin, B-Opacifications seen in plain radiography and C-Photomicrograph of the excised lesion (Note the large Calcium deposit visible in the scrotal dermis in the micrograph - Haematoxylin and Eosin $\times 40$ ).

Ceylon Medical Journal 2021; 66: 100-101

DOI: http://doi.org/ 10.4038/cmj.v66i2.9474

${ }^{1}$ District General Hospital, Nuwaraeliya, Sri Lanka.

Correspondence: BJ, e-mail: <bingumalj@gmail.com>. Received 23 January 2021 and revised version 02 June 2021 accepted 15 June 2021

This is an open-access article distributed under the terms of the Creative Commons Attribution License, which permits unrestricted use, distribution, and reproduction in any medium, provided the original author and source are credited. 
Abnormal deposition of insoluble calcium salts in skin and subcutaneous tissues is termed as Calcinosis Cutis [1]. Idiopathic Calcinosis Cutis is a distinct subtype, which occur without underlying tissue anomaly/damage or metabolic disorder. SC is a form of Idiopathic Calcinosis Cutis [1]. This entity was first described by Lewinski in 1883 and the first detailed case series analysis was performed by Shapiro and colleagues [2]. There are a few theories postulated on the pathogenesis. Whether these calcified nodules truly represent an idiopathic disease or whether they arise from epidermal/epidermoid/eccrine cysts as dystrophic calcification is still debated [1,3]. Further, Dartos muscle degeneration causing dystrophic calcification has been hypothesized as an aetiology $[1,3,4]$. SC generally do not cause much symptoms and interventions are commonly due to aesthetic disfigurement. Surgical excision and primary closure or complex reconstruction has been the main stay of management [2-4]. Many authors suggest complete excision of all minute nodules to prevent recurrence [2-5]. Laser therapy has been successfully utilized in management of SC recently [5,6].

\section{Authors' contributions}

$\mathrm{ZA}, \mathrm{NN}, \mathrm{AD}$ and $\mathrm{BJ}$ were involved in clinical management of the patient. SS reviewed the histopathology of the excised specimen. ZA, NN and AD drafted the manuscript. SS and BJ critically revised the draft. All authors approved the final submission.

\section{Conflicts of interest}

All authors have nothing to disclose.

\section{References}

1. Reiter N, El-Shabrawi L, Leinweber B, Berghold A, Aberer E. Calcinosis cutis. J Am Acad Dermatol 2011; 65: 1-12.

2. Shapiro L, Platt N, Torres-Rodriguez VM. Idiopathic calcinosis of the scrotum. Arch Dermatol 1970; 102: 199-204.

3. Syed MMA, Rajbhandari A, Paudel U. Idiopathic calcinosis cutis of the scrotum: a case report and review of the literature. J Med Case Rep 2018: 12: 366. doi.org/10.1186/ s13256-018-1922-6

4. Khallouk A, Yazami OE, Mellas S, Tazi MF, El Fassi J, Farih MH. Idiopathic scrotal calcinosis: a non-elucidated pathogenesis and its surgical treatment. Rev Urol 2011; 13: 95-7.

5. Meissner M, Kleemann J, Kaufmann R, Ochsendorf F. The erbium: YAG laser: A new technique for the treatment of scrotal calcinosis. J Eur Acad Dermatol Venereol 2017; 31: 207-9.

6. Cannarozzo G, Bennardo L, Negosanti F, Nisticò SP. $\mathrm{CO}_{2}$ Laser Treatment in Idiopathic Scrotal Calcinosis: A Case Series. J Lasers Med Sci 2020; 11: 500-1. 